\title{
Lodo de esgoto e suas potencialidades agrícolas
}

\author{
Sewage sludge and its agricultural potential \\ Lodos de depuradora y su potencial agrícola
}

Recebido: 26/01/2022 | Revisado: 03/02/2022 | Aceito: 11/02/2022 | Publicado: 16/02/2022

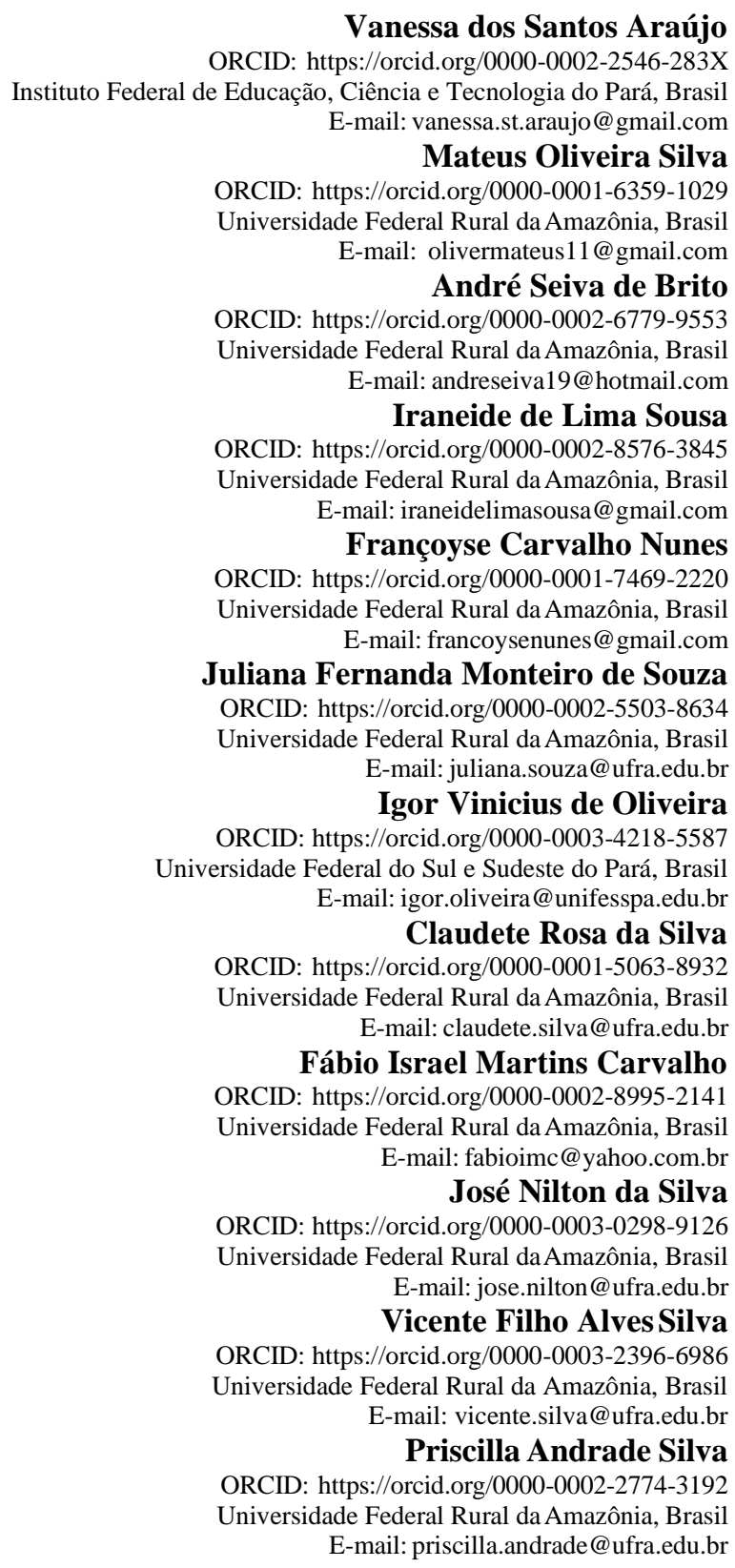

\section{Resumo}

O esgoto é constituído pela água usada nas atividades diárias, que foi usada para lavar roupa ou louça, no banho, na descarga do banheiro ou na pia. Esta água residual contém impurezas, constituída de uma mistura de detritos, restos de alimentos, detergentes, urina, fezes e outras substâncias. Quando jogado diretamente no meio ambiente, gera odor forte e fétido, além de conter bactérias nocivas, causadoras de enfermidades. Quando devidamente tratado, o lodo é chamado de biossólido, e sua reutilização agroflorestal pode ser uma alternativa atraente. Desse modo, o presente estudo tem como objetivo identificar o biossólido, caracterizar o processo de tratamento e a composição do material, relatar suas utilidades associadas a agricultura e recuperação de áreas degradadas, assim como normativas e legislações que vigoram a respeito desse resíduo. O trabalho foi conduzido por meio de levantamento bibliográfico que reúnem assuntos 
relevantes sobre o biossólido, características do biossólido, lodo de esgoto, utilização na agricultura, a fim de disponibilizar um conhecimento mais esclarecedor e relevante para a comunidade científica na área de tratamento de lodo de esgoto, convertendo-o em biossólido, sua caracterização e aplicação na agricultura nos mais variados aspectos. Palavras-chave: Solo; Dejeto; Utilização.

\begin{abstract}
The sewage consists of the water used in daily activities, used for washing clothes or dishes, in the shower, in the toilet flushing or in the sink. This waste water contains impurities, consisting of a mixture of debris, food scraps, detergents, urine, feces and other substances. When thrown directly into the environment, it generates a strong and fetid odor, in addition to containing harmful bacteria, causing diseases. When properly treated, sludge is called biosolid, and its agroforestry reuse can be an attractive alternative. Thus, the present study aims to identify the biosolid, characterize the treatment process and the composition of the material, report its utilities associated with agriculture and recovery of degraded areas, as well as regulations and legislation in force regarding this residue. The work was carried out through a bibliographic survey that brings together relevant subjects about biosolids, characteristics of biosolids, sewage sludge, use in agriculture, in order to provide a more enlightening and relevant knowledge for the scientific community of sewage sludge treatment area, converting it into biosolid, its characterization and application in agriculture in the most varied aspects.
\end{abstract}

Keywords: Ground; Waste; Use.

\title{
Resumen
}

Las aguas residuales consisten en el agua utilizada en las actividades diarias, que se utilizó para lavar la ropa o los platos, en la ducha, descargar el inodoro o en el fregadero. Estas aguas residuales contienen impurezas, que consisten en una mezcla de desechos, restos de comida, detergentes, orina, heces y otras sustancias. Al ser arrojado directamente al ambiente, genera un olor fuerte y fétido, además de contener bacterias dañinas, causantes de enfermedades. Cuando se tratan adecuadamente, los lodos se denominan biosólidos y su reutilización agroforestal puede ser una alternativa atractiva. Así, el presente estudio tiene como objetivo identificar el biosólido, caracterizar el proceso de tratamiento y la composición del material, reportar sus utilidades asociadas a la agricultura y recuperación de áreas degradadas, así como la normativa y legislación vigente respecto a este residuo. El trabajo se realizó a través de un levantamiento bibliográfico que reúne temas relevantes sobre biosólidos, características de los biosólidos, lodos de depuradora, uso en la agricultura, con el fin de brindar un conocimiento más esclarecedor y relevante para la comunidad científica en el área de lodos de depuradora. tratamiento de aguas residuales, convirtiéndolas en biosólidos, su caracterización y aplicación en la agricultura en los más variados aspectos.

Palabras clave: Tierra; Estiércol; Usar.

\section{Introdução}

$\mathrm{Na}$ produção industrial de fertilizantes, existe uma demanda muita elevada de energia fóssil para o processo de fabricação, influenciando significativamente no aumento do custo energético e ambiental (Tavares; Monteiro, 2014), em contrapartida existe o intenso crescimento populacional e o aumento dos índices de cobertura e de métodos para melhorar o processo de tratamento do esgoto no mundo, já que nas últimas décadas têm aumentado a produção desse resíduo. Por ser um passivo ambiental ele deve ser disposto de forma correta. No mundo, entre as alternativas de disposição mais comuns têm-se a incineração, disposição em aterros, aplicação no solo (com finalidades agrícolas ou recuperação de áreas degradadas) e outros usos (por exemplo, na construção civil ou como adsorvente) (Collivignarelli et al., 2019).

No Brasil, os sistemas de tratamento biológico mais usual do lodo são as lagoas de estabilização, porém devido a problemática do volume de lodo produzido pelas lagoas, não tem sido dada a devida atenção, a falta de importância também aplica-se na sua disposição desse resíduo. Entre as opções disponíveis tais como, a incineração, deposição oceânica e florestal e a utilização agrícola como fertilizante, tem sido considerada promissora (Sampaio et al., 2012). O lodo de esgoto possui elevadas quantidades de nutrientes e potencial para uso agrícola seja como provedor de nutrientes ou condicionador de solo (Paz-ferreiro et al., 2018), devido ao seu potencial em melhorar as propriedades físicas, químicas e biológicas do solo e aumentos na produtividade dos cultivos, por isso o aumento no rendimento se deve à melhoria de alguma propriedade que antes impedia o crescimento da cultura, como fornecimento de determinado nutriente, retenção de água, porosidade, entre outros fatores (Laird et al., 2017; Yu et al., 2019).

Em trabalhos desenvolvidos por Faria et al. (2017) o incremento na produtividade de grãos foi acoplado ao aumento na 
absorção de macro e micronutrientes, com exceção do Potássio, indicando que o incremento de produtividade poderia ser potencializada desde que houvesse a complementação potássica no lodo.

O biossólido é considerado tão atrativo para a o uso na agricultura devido a presença de nutrientes como o nitrogênio, fósforo e potássio pois além de conterem elevado teor de matéria orgânica ainda exercem o papel de condicionadores do solo. Desse modo, o uso do biossólido pode substituir parcialmente a utilização de adubos químicos (Freddi, 2019). De modo comprovado, o biossólido é considerado uma fonte alta qualidade de matéria orgânica, devido sua capacidade de potencializar as propriedades físicas do solo, além de conter fósforo e nitrogênio, e outros nutrientes em teores mais baixos. (Sampaio et al., 2012).

No brasil em condições tropicais, existem muitos estudos relacionadas as consequências da aplicação do lodo sobre as características do solo. O lodo de esgoto, e seus usos de na recuperação de áreas degradadas demonstram melhorias nas características físicas atuando positivamente sobre a formação de agregados, porosidade e retenção de água no solo, neste, o teor de água retido no solo saturado e a 0,006 MPa aumentou em função da aplicação de até de $20 \mathrm{t} \mathrm{ha}^{-1}$ de lodo de esgoto aos seis meses (Sampaio et al., 2012).

A presença de metais pesados é considerada uma das maiores limitações ao uso do lodo em solos agricultáveis. Em sua maioria, as concentrações de metais encontradas no lodo são mais elevadas que as encontradas naturalmente em solos, surge-se então a necessidade de avaliação dos riscos associados a elevação desses elementos no ambiente como resultado da aplicação desse resíduo (Messias et al., 2007).

Desse modo, o presente estudo tem como objetivo identificar o biossólido, caracterizar o processo de tratamento e a composição do material, relatar suas utilidades associadas a agricultura e recuperação de áreas degradadas, assim como normativas e legislações que vigoram a respeito desse resíduo.

\section{Metodologia}

Esta pesquisa utilizou como método a revisão integrativa da literatura que, segundo Souza, Silva e Carvalho (2010), "é um método que proporciona a síntese de conhecimento e a incorporação da aplicabilidade de resultados de estudos significativos na prática". Por se tratar de um estudo de revisão sistemática da literatura, o objetivo deste não envolve seres humanos, logo, não há a necessidade de aprovação por Comitê de Ética em Pesquisa (CEP) para a pesquisa. A opção por esta modalidade se dá por incluir diferentes tipos de estudos, que permite uma visão panorâmica do estudo de interesse.

A revisão sistemática da literatura foi realizada, entre agosto / 2021 e janeiro / 2022, por meio do portal da Scientific Electronic Library Online - SciELO e do Google Scholar utilizando pesquisa avançada com a combinação dos descritores "biossólido, características do biossólido, lodo de esgoto, agricultura, metais, patógenos, utilização". Essas bases de dados e bibliotecas digitais foram escolhidas por concentratrem periódicos bem qualificados a nível nacional e internacionalmente e serem referência para muitos pesquisadores brasileiros (Melo et al., 2022).

Assim como realizado por Melo et al. (2022), a seleção dos artigos baseou-se nos seguintes critérios: publicações nacionais e internacionais que responderam a busca avançada, sem restrição de período de tempo, com vistas a compreender a historicidade das pesquisas sobre a temática. Definiu-se como critério de inclusão: 70\% dos artigos publicados nos anos de 2011 a 2021; publicados nacionalmente e internacionalmente, em português e inglês. A análise dos estudos foi realizada de forma descritiva, onde possibilitou observar, descrever e classificar os dados sobre o biossólido e sua utilização na agricultura. Não houve a utilização de ferramentas digitais para categorização e análise dos resultados.

\section{Biossólido: Lodo de Esgoto}

O lodo de esgoto é definido pela Norma Técnica Brasileira (NBR) $\mathrm{n}^{\circ}$ 12.209/2011 como suspensão aquosa de 
componentes minerais e orgânicos separados no sistema de tratamento de esgoto, que para ser descartado necessita de tratamento para redução de sólidos biodegradáveis e odores, estabilização da matéria orgânica, redução de volume e combate a presença de vetores, o lodo de esgoto tratado e estabilizado para o descarte passa a denominar-se biossólido (Abreu, 2014)

O esgoto é constituído pela água usada nas atividades diárias, que foi usada para lavar roupa ou louça, no banho, na descarga do banheiro ou na pia. Esta água residual contém impurezas, constituída de uma mistura de detritos, restos de alimentos, detergentes, urina, fezes e outras substâncias. Quando jogado diretamente no meio ambiente, gera odor forte e fétido, além de conter bactérias nocivas, causadoras de enfermidades, ou seja, se não tratado adequadamente, o esgoto se torna um perigo ao meio-ambiente, além de ser fonte de doenças. (Westphalen et al., 2004).

Diante do crescimento da população humana, há um aumento relevante de problemas relacionados aos recursos hídricos (Santos et al., 2010). É possível afirmar que uma das origens da contaminação da água e do solo é o despejo não adequado de efluentes ao meio ambiente (Beltrame et al., 2016).

Os esgotos podem ser definidos de acordo com sua origem formadora, resíduos gerados nas residências formam o esgoto doméstico, os derivados das águas de chuva, o pluvial. Também chamado dejeto, o esgoto é grande gerador de poluição e de transmissão de doenças. Quando jogado diretamente no meio ambiente, gera odor forte e fétido, além de conter bactérias nocivas, como as coliformes fecais (Escherichia coli), causadoras de enfermidades, o que significa que a água por elas infectada se torna um risco para a saúde pública pois o esgoto não tratado contém agentes patogênicos, resíduos tóxicos e microrganismos que provocam o crescimento de outros tipos de bactérias, vírus ou fungos contaminadores e transmissores de doenças (Alves et al., 2021; Zoghlami et al., 2020).

Quando devidamente tratado, o lodo é chamado de biossólido, e sua reutilização agroflorestal pode ser uma alternativa atraente, tanto para os produtores de biossólido, que passam a depositar seu resíduo na natureza de forma mais sustentável, como também para os quem recebe, pois passam a receber um material rico em nutrientes e matéria orgânica, em grande quantidade e com baixo custo (Abreu et al., 2019).

\subsection{Caracterização do lodo do esgoto}

O tratamento de esgotos consiste, de maneira genérica, num conjunto de processos físicos, químicos e biológicos que resultam na remoção dos sólidos sedimentáveis e da matéria orgânica das águas residuais. Como resultado, é produzido o lodo, um resíduo sólido, em quantidade e composição variáveis em função das características do efluente e dos processos de tratamento adotados. No Brasil, a caracterização do Lodo de esgoto torna-se importante uma vez que a rede de coleta residencial não é, na maioria das vezes, separada da rede de coleta industrial. Isto faz com que exista maior probabilidade de ocorrência de dejetos industriais no lodo que restrinjam seu uso alternativo (Westphalen et al., 2004).

\subsubsection{Presença de agentes patogênicos}

Devido ser alto em concentração de nutrientes, o biossólido apresenta potencial de uso como fertilizante e condicionador do solo, assim como deve atender aos requisitos necessários em concentração de patógenos, podendo substituir parcial ou totalmente os fertilizantes minerais. Ainda assim, a aplicação direta do mesmo em solos agrícolas não é recomendada, necessitando a implementação de tratamentos que possibilitem a estabilização do biossólido objetivando reduzir odores, patógenos e a atração de vetores que podem ser consequência da decomposição do material depositado (Rigby et al., 2016).

De acordo com Straus (2000), para que seja passível de aplicação em áreas agrícolas, o lodo de esgoto deve passar por tratamentos que garantam um lodo de esgoto com número reduzido de patógenos e, dessa forma, atenda às normas da CETESB (1999). O autor ainda afirma também que, de acordo com os processos e parâmetros do tratamento do lodo, o consequente lodo de esgoto poderá ser caracterizado nas classes A ou B, como mostra a tabela 1. No entanto, a comercialização do lodo de esgoto 
para uso agrícola só é permitida quando o material se encontra na primeira classe.

Tabela 1. Classificação do lodo de esgoto em função dos processos de redução dos patógenos

\begin{tabular}{|c|c|c|}
\hline Lodo de esgoto & Classificação & Processo de redução de patógenos \\
\hline Classe A & $\begin{array}{c}\text { Coliformes fecais: } \\
\text { densidade < } 10^{3} \text { NMP.g.ST }{ }^{1} \text { e } \\
\text { Salmonella sp: } \\
\text { Densidade < 3NMP.g.ST }{ }^{1} \text {. }\end{array}$ & $\begin{array}{c}\text { Compostagem } \\
\text { Secagem térmica } \\
\text { Tratamento térmico } \\
\text { Digestão aeróbia termofílica } \\
\text { Irradiação } \\
\text { Pasteurização }\end{array}$ \\
\hline Classe B & $\begin{array}{c}\text { Coliformes fecais: densidade }<2.10^{6} \\
\text { NMP.g.ST }{ }^{1} \text { em pelo menos uma } \\
\text { amostra e Coliformes fecais: média } \\
\text { geométrica da densidade de sete } \\
\text { amostras }<2.10^{6} \text { NMP.g.ST }{ }^{1} \text { ou }<2.10^{6} \\
\text { UFC.g.ST }{ }^{2} .\end{array}$ & $\begin{array}{c}\text { Digestão aeróbia ou anaeróbia } \\
\text { Secagem } \\
\text { Compostagem } \\
\text { Estabilização com cal }\end{array}$ \\
\hline
\end{tabular}

${ }^{1}$ NMP/.. ST: Número Mais Provável por grama de Sólidos Totais. ${ }^{2}$ UFC/g. ST: Unidades Formadoras de Colônias por grama de Sólidos Totais. Fonte: CETESB (1999).

A disposição final do lodo pelas suas próprias características qualitativas e quantitativas é um dos principais problemas que envolvem uma estação de tratamento de esgotos. Como resultado, o tratamento de esgoto gera o efluente tratado, que é lançado nos rios, podendo gerar outros subprodutos como a escuma, gases e lodo de esgoto, por isso é necessário um tratamento e destinação final de modo adequado a fim de evitar impactos ambientais ou até mesmo prejudicar o sistema de coleta e tratamento de esgotos (Andreoli et al., 2014).

De acordo com a CETESB, (1999), o lodo de esgoto Classe A não apresenta restrições de uso, no entanto, o de Classe B exige alguns cuidados tais como: evitar contato manual com o material ou com a área contemplada para a sua aplicação por pelo menos trinta dias; não cultivar, por 14 meses após a aplicação, alimentos cuja parte consumida entre em contato com o lodo de esgoto e; por fim, não poderão ser cultivados na área, por um período mínimo de nove meses e no máximo 38 meses, alimentos que se desenvolvam no subsolo.

\subsubsection{Presença de metais pesados}

No lodo, os componentes perigosos são os metais pesados, as bactérias, vírus, protozoários e helmintos. A descarga desses componentes, bem como a dos nutrientes nitrogênio e fósforo na superfície e no lençol freático, deve ser minimizada para que se evite a degradação da qualidade da água (Pereira et al., 2013).

A presença de metais pesados, é uma das principais limitações ao uso do lodo na agricultura, pois pode causar a contaminação do solo, lençol freático, plantas e animais (Eid et al., 2021). A concentração de metais pesados presentes no lodo pode variar de acordo com o tipo de esgoto que a estação de tratamento recebe, sendo que o esgoto industrial, em comparação ao esgoto doméstico, possui concentração de metais pesados mais elevada (Tytła et al., 2016).

As concentrações de metais presentes no lodo, de modo geral, são bem maiores do que aquelas naturalmente encontradas em solos, surgindo à necessidade de monitorar o ambiente devido os riscos do aumento desses elementos, em consequência do uso na agricultura do biossólido (Alves et al., 2021). A aplicação do lodo de esgoto em solos agricultáveis pode gerar aumento no teor de sódio do solo, afetando assim a absorção de água e de nutrientes pelos vegetais, devido ao aumento da pressão osmótica da solução do solo, ou de forma indireta, pela sua ação dispersante sobre as argilas, desestruturando o solo e prejudicando a infiltração de água, aeração e crescimento das raízes (Garcia et al., 2009; Paes et al., 2013; Paes et al., 2014). 
Metais pesados como chumbo $(\mathrm{Pb})$, mercúrio $(\mathrm{Hg})$, cádmio $(\mathrm{Cd})$, arsênico $(\mathrm{As})$, cromo $(\mathrm{Cr})$, zinco $(\mathrm{Zn})$, cobre $(\mathrm{Cu})$, manganês (Mn) e níquel (Ni) dentre outros são considerados os metais de maior interesse em termos de saúde pública (Peirano, 2003). Alguns deles são nutrientes importantes no desenvolvimento da vida. Porém, em teores elevados, podem causar sérios riscos para o desenvolvimento das plantas e para a saúde dos animais. Assim, o grande problema é o risco de acumulação desses elementos nos solos, nas plantas, nos animais, com especial destaque ao organismo humano (Segura-Muñoz et al., 2003).Esses elementos estão presentes em diversos tipos dos resíduos e despejos gerados em atividades humanas, podendo passar para o esgoto sem prévio tratamento. A presença de metais pesados no lodo de esgoto tem sido objeto de muitos estudos devido ao impacto ambiental desses elementos na saúde humana e animal e na qualidade dos alimentos. (Poleto; Martinez, 2011).

Atualmente a reciclagem agrícola do lodo sofre resistência da sociedade decorrente dos potenciais danos ambientais, agronômicos e sanitários. Durante o processo de tratamento de efluentes agroindustriais, é gerada uma biomassa, denominada lodo ou biossólido, composta basicamente por microrganismos e matéria orgânica. Esse resíduo causa um grave impacto ambiental se for disposto em sua forma in natura, portanto, é imprescindível que haja um tratamento a fim de estabilizar esse biossólido (Silva, 2018). Como as regulamentações garantem a qualidade dos biossólidos em relação ao seu conteúdo de metais e ao risco de problemas sanitários, alternativas de secagem, estabilização e de formas de processamento avançado têm apresentado um grande crescimento (Pereira et al., 2013).

A fitodisponibilidade desses metais sofre interferência de atributos do solo, natureza do elemento, presença de outros elementos, atividade biológica e fatores ambientais. Em geral, esses elementos formam complexos com a matéria orgânica, diminuindo sua mobilidade no solo. No entanto, com a formação de complexos de baixo peso molecular pode ocorrer movimentação em profundidade. $\mathrm{O}$ autor ainda alega que, nos solos de maneira geral, os metais pesados comportam-se dependendo dos seguintes atributos: $\mathrm{pH}$, quantidade e natureza da matéria orgânica, potencial redox, tipologia e quantidade da argila, CTC e textura do solo (Campos, 2010).

Os solos da região dos trópicos sofrem muito intemperismo e possuem em sua composição mineralógica a predominância de caulinita, óxidos-hidróxidos de ferro e alumínio. Estes minerais influenciam diretamente nos atributos físicos, químicos e mineralógicos dos solos, pois apresentam variação na cristalinidade e apresentam cargas que dependem do $\mathrm{pH}$ do solo (Vendrame et al., 2011). Em solos altamente intemperizados, os principais fatores limitantes em relação à fertilidade são: elevada acidez, baixa Capacidade de Troca de Cátions (CTC) e ânions (CTA) e deficiência de N, P, K, S, Ca, Mg, B, Cu e Zn (Mumbach et al., 2018).

A Companhia de Tecnologia de Saneamento Ambiental, ligada à Secretaria do Meio Ambiente do governo paulista (CETESB), por sua vez, possui normas que se restringem aos resíduos de tratamento biológico não enquadráveis na legislação, dentre as quais estabelece parâmetros aos teores aceitáveis de metais no biossólido, especificados na Tabela 2.

Tabela 2. Teores máximos de metais pesados permitidos no lodo de esgoto para uso agrícola.

\begin{tabular}{cccccccccc}
\hline Metal & As & Cd & Cu & Pb & Hg & Mo & Ni & Se & Zn \\
\hline $\begin{array}{c}\text { Conc. máx } \\
\left(\mathrm{mg} \mathrm{kg}^{-1}\right)\end{array}$ & 75 & 85 & 4300 & 840 & 57 & 75 & 420 & 100 & 7500 \\
\hline
\end{tabular}

Conc. máx.: Concentração máxima. Fonte: CETESB (1999).

Avaliações do efeito da aplicação de biossólido na disponibilidade de nutrientes e metais pesados no milho, no Paraná principalmente no que se refere ao $\mathrm{Cd}$, a adubação com biossólido resultou em acúmulo deste metal pesado tóxico no solo, resultado que causa preocupação (Gonçalves Jr. et al., 2009). 


\subsection{O uso agrícola}

Um composto bem maturado é rico em coloides húmicos, que age nas propriedades químicas, físicas e biológicas do solo. A qualidade estrutural do solo refere-se à organização das partículas do solo o que constitui um ambiente dinâmico, na qual a alteração desse sistema determinará um novo comportamento dos processos ocorridos no solo (Ferreira, 2010).

A formação destes agregados depende de elementos de ligação, que funcionam como uma espécie de "cola" na sua estruturação. Estes elementos de ligação são os coloides, que podem ser minerais (argilas) ou orgânicos (húmus). Os coloides além de estruturar o solo, também se constituem na parte quimicamente ativa do sistema, armazenando os nutrientes mais solúveis, que são os alimentos das plantas. A capacidade do solo em armazenar cátions é conhecida como CTC (Capacidade de Troca Catiônica) (Melo \& Marques, 2000).

A aplicação sucessiva de composto de lixo urbano em cultivo de girassol e milho promoveu diminuição na acidez potencial e aumentou os valores de pH, capacidade de troca de cátions, saturação por bases e teores de cálcio e magnésio trocáveis do solo (Strojaki et al., 2013).

O húmus estável do solo está constantemente se mineralizando, ou seja, a cada ano o solo perde parte de seu estoque de húmus. A correta gestão do estoque de húmus de um solo é um dos objetivos da boa prática agrícola. O estoque de húmus do solo pode ser reposto. Estudos em países de clima temperado mostraram que cerca de $4 \%$ dos restos de culturas deixadas no solo se transformam em húmus estável, sendo o resto simplesmente mineralizado. Em países quentes e chuvosos, como o Brasil, esta taxa de conversão deve ser ainda menor (Henry et al., 1994).

A taxa de transformação de matéria fresca em húmus salta para 20-40\% quando os resíduos passam pelo processo de compostagem. Estas reflexões são necessárias porque além de ser um processo de tratamento de resíduos, a compostagem é uma "fábrica" de húmus estável para o solo. Portanto, quando se discute uso do composto, é preciso evitar o erro simplório de fixar seu valor apenas no seu teor de nutrientes. Evidentemente, os nutrientes, principalmente o nitrogênio e fósforo, estão bem representados no composto produzido a partir de lodo e tem valor econômico importante, porém, o valor agronômico do composto vai além dos nutrientes minerais (Gonçalves, 1998).

O lodo de esgoto quando é tratado, de forma adequada recebe o nome de biossólido e adquire propriedades que permitem seu uso na agricultura (Silva et al., 2020). Esse material é de natureza majoritariamente orgânica, possuindo altas quantidades de nitrogênio e fósforo, podendo diminuir a necessidade de utilização de fertilizantes nitrogenados e fosfatados, já que o último não é um elemento renovável (Rehman et al., 2018).

Várias pesquisas concluíram que o lodo de esgoto levou ao desenvolvimento e produtividade maior ou igual ao proporcionado pelos fertilizantes convencionais. Em um estudo a produtividade do girassol, devido a substituição da fertilização inorgânica por lodo de esgotos aumentou linearmente a produtividade de grãos em função da aplicação deste biossólido. Estudos realizados em um argissolo vermelho de textura média sofreram incrementos nos teores de $\mathrm{Ca}$ e $\mathrm{Mg}$ em função da aplicação de biossólido (Krob et al., 2011; Strojaki et al., 2013). Em outra pesquisa a utilização de lodo de esgoto como fertilizante permite ganhos ao produtor, pelos mesmos motivos, ou seja, aumento da produtividade das culturas e redução do uso de fertilizantes minerais (Guedes et al., 2006).

\section{Efeito do Lodo de Esgoto nas Propriedades do Solo}

Os compostos orgânicos atuam como condicionadores do solo, melhorando suas características físicas, químicas e biológicas (Araujo Neto et al., 2010), mantendo o solo úmido e reduzindo a contração das argilas expansivas, evitando os danos ao sistema radicular, típicos de ocorrência em solos argilosos, podendo contribuir para aumentar a produtividade, melhorar a qualidade dos frutos e a rentabilidade da cultura (Tavella et al., 2010). 
Novaes et al. (2007) destacam que, além do efeito químico, o maior benefício da matéria orgânica é na biologia do solo, pois é rica em agentes cimentantes, como polissacarídeos, hifas fúngicas e compostos aromáticos, que promovem a agregação de partículas, confere maior estabilidade aos agregados por retardar a entrada de água nesses, aumentando sua resistência quando umedecidos.

O composto é um condicionador de solo, que atua beneficamente nas suas propriedades físicas, químicas e biológicas, além de fornecer nutrientes. Sua ação é diferente dos fertilizantes minerais. Também deve ser observado que não deve existir qualquer tipo de antagonismo entre o uso do composto e o dos fertilizantes minerais. O composto não deve ser visto como um substituto do fertilizante mineral, mas sim como um produto que deve ser usado em harmonia com o fertilizante mineral (Guedes et al., 2006). Por isso, pode ser utilizado nos setores agroflorestais como biofertilizante, sendo uma alternativa ecologicamente correta e economicamente viável (Deus et al., 2020).

\subsection{Propriedades físicas}

Dentre os efeitos do lodo de esgoto sobre as propriedades físicas do solo, condicionadas principalmente pela presença de matéria orgânica, destacam-se a melhoria no estado de agregação das partículas do solo, com consequente diminuição da densidade e aumento na aeração e retenção de água (Cezar et al., 2011).

\subsection{Propriedades química}

Ao se referir aos aspectos químicos, a aplicação de lodo ao solo tem propiciado aumento nos teores de elementos como o fósforo, sendo essencial e, portanto, limitante para o crescimento dos vegetais. Já que não pode ser produzido sinteticamente ou substituído por qualquer outra, os biossólidos possuem altos teores de fósforo (Rastettert \& Gerhardt, 2017).

A aplicação do lodo melhora também o complexo sortivo em relação aos cátions $\mathrm{K}+, \mathrm{Ca}++, \mathrm{Mg}++$ e algumas vezes o $\mathrm{Na}+$, elevando a soma de bases do solo, principalmente quando o resíduo é tratado com calcário. Em contrapartida, é comum a presença de metais pesados, que em concentrações superiores às legalmente recomendadas, têm sido responsabilizados por causar agravos à saúde, além de uma série de doenças carcinogênicas. Os efeitos tóxicos desses metais encontram-se amplamente descritos na literatura, sendo que a gravidade depende do grau de exposição aos mesmos (Ferrer et al., 2011).

Os teores mais elevados de metais no solo têm sido observados com frequência em diversas áreas que sofreram ações antrópicas, como sucessivas adições de fertilizantes, corretivos e pesticidas, por meio de deposições atmosféricas e, principalmente, pelo uso de resíduos como escórias e lodos de esgoto. E as aplicações sucessivas de lodo de esgoto podem conduzir ao acúmulo destes elementos no ambiente e a entrada na cadeia alimentar (Baird; Cann, 2011).

\subsection{Propriedades biológicas}

Os microrganismos que estão presentes no esgoto se alimentam do material orgânico, formando o lodo e atenuando assim, a carga poluidora do efluente, com o objetivo de concentrar o lodo para a biodegradação, seguido de uma aeração com intuito de fornecer oxigênio para o efluente através de difusores, com a técnica do ar difuso (Silva et al., 2018).

Os microrganismos são sensíveis a qualquer alteração no solo e têm um papel fundamental na transformação das substâncias. E por isso os atributos microbianos mais frequentemente avaliados, são a atividade microbiana avaliada pela respiração basal do solo, que é o comportamento da atividade dos microrganismos em função das perturbações no solo aumentando a disponibilidade de recursos limitados, e a biomassa microbiana, que tem sido parâmetros mais utilizados para avaliar o impacto do uso de resíduos (Stromberger et al., 2011). Segundo os autores, a adição de lodo de esgoto ao solo estimula a atividade microbiana, acelerando a decomposição das frações lábeis e contribuindo para a manutenção dos teores de matéria orgânica (Vaz \& Gonçalves 2002). 


\section{Uso Agrícola do Lodo de Esgoto sob Aspectos Legais}

A maioria das cidades brasileiras não apresentam rede de coleta de esgotos e/ou estações de tratamento dos mesmos. $\mathrm{O}$ despejo do lodo nas estações de tratamento de esgoto (ETE) também pode ser uma alternativa adequada, a menos que em seu projeto constate a possibilidade de tratamento da carga orgânica e que seja antevista uma estrutura exclusiva onde o lodo será recebido. Tal estrutura deve levar em consideração desde as manobras dos caminhões, a descarga do lodo de modo controlado, até os sistemas de pré-tratamento específicos para o lodo (Carvalho \& Andreoli, 2015).

O lodo de esgoto, é um subproduto oriundo de Estações de Tratamento de Esgoto (ETE's) e vem se mostrando como uma opção viável à adubação orgânica. A disposição comum desse material é em aterros sanitários com elevados custos para manutenção, sendo assim, a utilização agrícola desse material é uma prática considerada mais sustentável e econômica (Bittencourt et al., 2017; Antonkiewicz et al., 2020). O uso do lodo de esgoto na agricultura apenas é recomendável quando este possuir teores de organismos patogênicos, compostos orgânicos e metais pesados permitidos pela legislação, que impossibilitará eventuais danos à cadeia trófica envolvida. Os teores de metais pesados são mais preocupantes uma vez que os organismos patogênicos são de fácil eliminação por processos de calagem e compostagem (CONAMA, 2006).

No Brasil, o Conselho Nacional do Meio Ambiente aprovou, em 2006, a Resolução no 375, que define critérios e procedimentos para o uso agrícola de lodos de esgoto sanitário e seus produtos derivados, definindo limites para substâncias potencialmente tóxicas e critérios para liberação do resíduo. Esta Resolução também define as culturas aptas a receberem lodo de esgoto ou produto derivado, sendo proibida a utilização de lodo de esgoto ou produto derivado em pastagens e cultivo de olerícolas, tubérculos, raízes e culturas inundadas, bem como as demais culturas cuja parte comestível entre em contato direto com o solo (CONAMA, 2006).

Devido possuir características favoráveis ao seu uso, o lodo de esgoto, nesse contexto, pode ser aplicados em plantios florestais como fertilizante ou condicionador do solo, pois pode atender tanto as demandas relativas à sustentabilidade dos plantios florestais, como balancear os passivos ambientais e econômicos relacionados à destinação dos mesmos, permitindo sua disposição de forma mais segura ao ecossistema e mais vantajosa economicamente. Para conservação e recuperação dos solos, uma das alternativas é o uso de lodo de esgotos domésticos em solos agricultáveis (Shizuo, et al., 2021).

A eliminação inadequada e não científica de biossólido, acarreta várias problemáticas ambientais desde a contaminação das águas subterrâneas, degradação do solo, até desequilíbrios na cadeia alimentar. Sendo assim, consoante com os princípios da hierarquia de gestão de resíduos, a reciclagem agrícola tornando se uma alternativa sustentável e uma opção mais coerente quando comparado aos métodos de disposição tradicionais (Srivastava et al., 2016). Portanto, é necessária uma regulamentação com mais rigor para que se possa adicionar o resíduo ao solo, assim como também é relevante estudos que determinem riscos ambientais a curto e longo prazos considerando os metais pesados presentes no biossólido (Barceloux, 1999).

Além disso, a Lei 12.305, de 02 de agosto de 2010, que instituiu a Política Nacional de Resíduos Sólidos (PNRS), dispõe sobre as diretrizes relativas à gestão integrada e ao gerenciamento de resíduos sólidos. Também identifica as responsabilidades dos geradores de resíduos e do poder público. Foi regulamentada pelo Decreto 7.404, de 23 de dezembro de 2010, que também criou o Comitê Interministerial da Política Nacional de Resíduos Sólidos e o Comitê Orientador para a Implantação dos Sistemas de Logística Reversa (Brasil, 2010).

Uma vez que o uso agrícola de lodo de esgoto envolve a adição de nutrientes e matéria orgânica ao solo, o Ministério da Agricultura, Pecuária e Abastecimento (MAPA) incluiu lodo de esgoto na Instrução Normativa (IN No 15 , de 24 dezembro de 2004, em resposta ao Decreto $\mathrm{n}^{\circ}$ 4954) que regulamenta o registro de fertilizantes orgânicos. Dessa maneira, para se obter o registro do lodo de esgoto junto ao MAPA, uma série de regras deverá ser respeitada, tanto em relação às garantias dos benefícios, como teor de nutrientes, como em relação à presença de contaminantes, como teor de metais pesados (Pires, 2006). 
A utilização do biossólido o Brasil, é experimentada cada vez mais em atividades agroflorestais e em alguns casos, é monitorada por universidades e instituições de pesquisa quanto ao seu uso (Rezende, 2005). Sobre a normatização para o despejo final do lodo de esgoto, o Brasil ainda não possui uma legislação específica. Entretanto, há algumas recomendações para as atividades de aplicações, que especifica a dose e a complementação mineral, com base em análise de solo (MOREIRA et al., 2019), além de receber monitoramento na área de aplicação do composto orgânico a partir de parâmetros agronômicos e teores de poluentes químicos (Kratz et al., 2013).

\section{Considerações Finais}

As indústrias em todos os municípios, encontram-se diante do gargalo do manejo de volumes maiores de resíduos, tanto os de natureza sólida, quanto de águas residuais, em seu tratamento primário e secundário. As lagoas de estabilização são um conjunto de processos de tratamento biológico mais usual no Brasil, contudo não é demandado uma importância significativa para os entraves relativos a quantidade de lodo gerado pelas lagoas, assim como a sua disposição.

O lodo de esgoto para ser utilizado na agricultura, deve apresentar características adequadas, atendendo todos os critérios estabelecidos dentro das normas. Além disso, um profissional habilitado deve ser responsável pelo seu uso monitorando as variações nos teores de metais pesados, compostos orgânicos e patógenos humanos, dentre outras características.

Vem sendo utilizado em substituição de lodo de esgoto, o termo biossólido, porém para diferenciar este resíduo que possui propriedades adequadas para o uso em culturas agroflorestais, após as modificações promovidas por microrganismos e o processo de higienização dos dejetos que o precederam. $\mathrm{O}$ uso do biossólido na composição de substratos é considerada uma opção viável para a disposição final deste resíduo, alegando a economia que esse material pode promover em relação aos fertilizantes e sobretudo, os benefícios ao meio ambiente.

Portando, este trabalho, exploratório e descritivo, buscou não só tentar entender algumas questões em relação ao biossólido, como ao mesmo tempo alçar questões mais aprofundadas a serem estudadas e pesquisadas posteriormente sobre a sua utilização como fonte de matéria orgânica e nutriente para o solo e plantas, como também proporcionar uma base de conhecimentos específicos para subsidiar legislações específicas para o despejo, tratamento e aplicação na agricultura

\section{Referências}

Abreu, A. H. M. de Alonso, J. M. Melo, L. A. de Leles, P. S. dos S. \& Santos, G. R. dos. (2019). Caracterização de biossólido e potencial de uso na produção de mudas de Schinus terebinthifolia Raddi. Eng. Sanit Ambient, 24 (3), 591-599. https://doi.org/10.1590/s1413-41522019108265

Abreu, A. H. M. (2014). Biossólido na produção de mudas florestais - Dissertação (Mestrado em Ciências Ambientais e Florestais). Universidade Federal Rural do Rio de Janeiro, Rio de Janeiro, 79.

Alves, P. F. S. Albuquerque, H. C. de. Sampaio, R. A. Zuba Junio, G. R. Fernandes, L. A. \& Rodrigues, M. N. (2021) Heavy metals and sodium concentrations in soil and sunflower crops fertilized with sewage sludge. Research, Society and Development. 10(12), 1-9. https://doi.org/10.33448/rsd-v10i12.20734

Andreoli, C. V. Von Sperling, M. \& Fernandes, F. (Org.). (2014). Lodo de esgotos: tratamento e disposição final. Belo Horizonte: Departamento de Engenharia Sanitária e Ambiental, UFMG Curitiba: SANEPAR, 484 p. Princípios do tratamento biológico de águas residuárias, 6.

Araújo Neto, S. E. de Galvão, R. O. Ferreira, R. L. F. Parmejiani, R. S. \& Negreiros, J. R. da S. (2010). Plantio direto de cebolinha sobre cobertura vegetal com efeito residual da aplicação de composto orgânico. Ciência Rural, Santa Maria, RS, 40(5). https://doi.org/10.1590/S0103-84782010000500033

Antonkiewicz, J. Popławska, A. Kołodziej, B. Ciarkowska, K. Gambuś, F. Bryk, M. \& Babula, J. (2020). Application of ash and municipal sewage sludge as macronutrient sources in sustainable plant biomass production. Journal of environmental management, London, $264(110450)$, $1-9$. https://doi.org/10.1016/j.jenvman.2020.110450

Baird, C. \& Cann, M. (2011). Química Ambiental. (4a ed.), Bookman. 844p.

Barceloux D. G. (1999). Journal Toxicol Clin Toxicology, 37(2), 272-292.

Beltrame, T. F. Beltrame, A. F. Lhamby, A. R. \& Pires, V. K. (2016). Efluentes, resíduos sólidos e educação ambiental: Uma discussão sobre o tema. Revista Eletrônica em Gestão, Educação e Tecnologia Ambiental. 20(1), 283-294. https://doi.org/105902/2236117015827 
Brasil. Lei $\mathrm{n}^{\circ}$ 12.305, de 02 de agosto de 2010. Diário Oficial [da] República Federativa do Brasil. Brasília, DF, 02 ago. 2010. Disponível em: http://www.planalto.gov.br/ccivil_03/_ato2007-2010/2010/lei/112305.htm. Acesso em: 19 jan. 2022.

Bittencourt, S. Aisse, M. M. \& Serrat, B. M. (2017). Gestão do uso agrícola do lodo de esgoto: estudo de caso do estado do Paraná, Brasil. Engenharia Sanitária e Ambiental, Rio de Janeiro, 22(6), 1129-1139. https://doi.org/10.1590/S1413-41522017156260

Campos, M. C.C. (2010). Atributos dos solos e riscos de lixiviação de metais pesados em solos tropicais. Ambiência. Guarapuava-PR, 6(3), 547-565.

Carvalho, E. H. \& Andreoli, C. V. (2015). Lodos de fossa e tanque séptico: orientações para Definição de Alternativas de Gestão e Destinação. 1. ed, 450p.

CETESB. (1999). Aplicação de lodos de sistemas de tratamento biológico em áreas agrícolas - critério para projeto e operação: manual técnico. São Paulo. ABIA, 4230.

Cezar, R. Silva, M. Colonese, J. Bidone, E. Egler, S. Castilhos, Z. \& Polivanov, H. (2011). Influence of the properties of tropical soils in the toxicity and bioavailability of heavy metals in sewage sludge-amended lands. Environmental Earth Science, 66(8), 2281-2292. https://doi.org/10.1007/s12665-011-1449-2

Collivignarelli, M. C. Canato, M. Abbà, A. \& Carnevale Miino, M. (2019). Biosolids: what are the different types of reuse? Journal of Cleaner Production, 238(117844), 1-21. https://doi.org/10.1016/j.jclepro.2019.117844

CONAMA - Conselho Nacional do Meio Ambiente. Resolução n 375 e n 380, de 29 de agosto de 2006, Brasília, DF: Conama, 2006. Disponível em: http://www.mma.gov.br/port/conama/res06/res37506.pdf. Acesso em: 20 jan. 2022.

Deus, A.S. Abrahão, R. Santos, R. F. Dos Araújo, L de S. Carneiro, K. de A. A. Uyeda, C. A. Demartelaere, A. C. F. Diniz, D. de P. Efeito do biossólido de indústria têxtil para o solo e para a produção do capim-elefante. Brazilian Journal of Development, 6(7), 50331-50348. https://doi.org/10.34117/bjdv6n7-620

Eid, E. M., Shaltout, K. H., Alamri, S. A. M., Alrumman, S. A., Hussain, A.A., Sewelam, N., El-Bebany, A. F., Alfarhan, A. H., Picó, Y., \& Barcelo, D. (2021). Prediction models based on soil properties for evaluating the uptake of eight heavy metals by tomato plant (Lycopersicon esculentum Mill.) grown in agricultural soils amended with sewage sludge. Journal of Environmental Chemical Engineering, 9(5), 105977. https://doi.org/10.1016/j.jece.2021.105977

Faria, W. M. Figueiredo, C. C. De Coser, T. R. Vale, A. T. \& Schneider, B. G.(2017). Is sewage sludge biochar capable of replacing inorganic fertilizers for corn production? Evidence from a two-year field experiment. Archives of Agronomy and Soil Science, 64(4), 505-519. https://doi.org/10.1080/03650340.2017.1360488

Ferreira, M. M. (2010). Caracterização física do solo. In: Lier, Q. J. van (ed.). Física do solo. Viçosa: Sociedade Brasileira de Ciência do Solo, 1-27.

Ferrer, A. Oña, J. De Osorio, F. Mochón, I. (2011). Evolution of the soi and vegetation cover on road embankments after the application of sewage sludge. Water Air Soil Pollution, 214(1-4), 231-240. https://doi.org/10.1007/s11270-010-0419-8

Freddi, L. A. (2019). Riscos associados à aplicação do lodo de esgoto na agricultura. Revista científica ANAP Brasil, 12(24), 1-11. https://doi.org/10.17271/19843240122420191982

Gonçalves Jr. A. C., Selzlein, C. Nacke, H. (2009). Uso de biomassa seca de aguapé (Eichornia crassipes) visando à remoção de metais pesados de soluções contaminadas. Acta Scientiarum Technology, 31(1), 103-108. https://doi.org/10.4025/actascitechnol.v31i1.3166

Gonçalves, R. F. (1998) Caracterização, técnica de remoção e reciclagem agrícola do lodo de lagoas de estabilização. Curitiba: PROSAB/FINEP, (Edital 01/96).

Guedes, M. C. Andrade, C.A.Poggiani, F. Mattiazzo, M. E.(2006). Propriedades químicas do solo e nutrição do eucalipto em função da aplicação de lodo de esgoto. Rev. Bras. Ciênc. Solo, 30(2), 267-280. https://doi.org/10.1590/S0100-06832006000200008

Henry, C. L. Cole, D. W. Harrison, R. B. (1994). Use of municipal sludge to restore and improve site productivity in forest: the pack forest sludge research program. Forest ecology and management, 66(1-3),137-149. https://doi.org/10.1016/0378-1127(94)90153-8

Kratz, D. Wendling, I. Nogueira, A. C. Souza, P. V. de. (2013). Propriedades físicas e químicas de substratos renováveis. Revista Árvore, Viçosa-MG, 37(6), 1103-1113. https://doi.org/10.1590/S0100-67622013000600012

Krob, A. D. Morais, S. P. Selbach, P. A. Bento, F. M. Camargo, F. A. O. (2011). Propriedades químicas de um Argissolo tratado sucessivamente com composto de lixo urbano. Ciência Rural, Santa Maria, 41(3). 433-439. https://doi.org/10.1590/S0103-84782011005000017

Messias, A. S. Silva, H. A. E Lima, V. N. De Souza, J. E. G. de. (2007). Avaliação da mobilidade de micronutrientes em solo tratado com lodo de esgoto. Revista Brasileira de Gestão e Desenvolvimento Regional. 3(3), 193-211. https://doi.org/10.54399/rbgdr.v3i3.93

Melo, W. J. Marques, M. O. (2000). Potencial do lodo de esgoto como fonte de nutrientes para as plantas. In: Bettiol, W. Camargo, O. A., eds. Impacto ambiental do uso agrícola do lodo de esgoto. Jaguariúna: EMBRAPA Meio Ambiente, 109-141.

Melo, C. J. de O. Silva, A. K. T. da Brito, A. S. de Beirão, A. T. M. Oliveira, J. T. de Silva, P. A. (2022) Cravo-da-índia e canela como saborizantes na formulação de doces de abóbora. In: Desafios e Estratégias para Segurança Alimentar Mundial. Ed: 1, Editora Amplla. 97-107. https://10.51859/amplla.des1788-9

Moreira, S.De F.. Santos, S. D. de O. Sardinha, A. S. Júnior, A. P. (2019). O Lodo de ETE como alternativa para a recuperação do solo em áreas degradadas. Brazilian Applied Science Review, Curitiba, 3(3), 1564-1585. https://doi.org/10.34115/basrv3n3-006

Montelo, B. M. Sindeaux, E. do N. Cunha, S.C. Sousa, V.C.S. Gatti, V.C. do M. Barata, H. da S. Silva, C. R. da . Silva, P. A. Coelho, A. L. (2021) O impacto da COVID-19 na saúde mental de enfermeiros que atuam na pandemia: uma revisão de literatura. Pesquisa, Sociedade e Desenvolvimento, 10(15),1-10. https://doi.org/10.33448/rsd-v10i15.22066

Mumbach, G. L. Oliveira, D. A. Warmling, M. I. Gatiboni, L. C. (2018). Quantificação de fósforo por Mehlich 1, Mehlich 3 e Resina Trocadora de Ânions em solos com diferentes teores de argila. Revista Ceres, 6(6),546-554. https://doi.org/10.1590/0034-737X201865060010 
Novaes, R. F. Alvarez V. H. Barros, N. F. Fontes, R. L. Cantarutti, R. B. \& Neves, J. C. L. (2007). Fertilidade do solo. Viçosa, MG: Sociedade Brasileira de Ciência do Solo, $1017 \mathrm{p}$.

Oliveira, F. C. Matiazzo, M. E. Marciano, C. R. \& Rosseto, R. (2002). Efeitos de aplicações sucessivas de lodo de esgoto em Latossolo Amarelo distrófico cultivado com cana-de-açucar: carbono orgânico, condutividade elétrica, pH e CTC. Rev. Bras. Ciênc. Solo, 26(2), 505-519. https://doi.org/10.1590/S010006832002000200025

Peirano, M. M. F. (2003). Remoção de metais pesados no tratamento biológico-sistema biológico tipo lodos ativados. Revista Gerenciamento Ambiental, 24, $51-53$.

Paz-Ferreiro, J. Nieto, A. Méndez, A. Askeland, M. \& Gascó, G. (2018). Biochar from biosolids pyrolysis: a review. International Journal of Environmental Research and Public Health, 15(5), 956. https://doi.org/10.3390/ijerph15050956

Pereira, R. D. Takenaka, E. M. M. \& Fluminhan Jr, A. (2013). Reciclagem agrícola de biossólidos: aspectos ambientais e aceitação pública. Colloquium Humanarum, Presidente Prudente, 10(2), 90-101, https://doi.org/10.5747/ch.2013.v10.n2.h145

Pires, A. M. M. (2006). Uso agrícola do lodo de esgoto: aspectos legais. Embrapa Meio Ambiente. Jaguariúna, 4.

Poleto, C. \& Martinez, L. L. C. (2011). Sedimentos Urbanos: Ambiente e Água. Holos Environment, 11(1), 1- 15. https://doi.org/10.14295/holos.v11i1.3053

Rastetter, N. \& Gerhardt, A. (2017). Toxic potential of different types of sewage sludge as fertiliser in agriculture: ecotoxicological effects on aquatic, sediment and soil indicator species. Journal of Soils Sediments, 15(3), 565-577. https://doi.org/10.1007/s11368-016-1468-4

Rehman, R. A. Rizwan, M. Qayyum, M. F. Ali, S. Zia-Ur-Rehman, M. Zafar-Ul-Hye, M. Hafeez, F. \& Iqbal, M. F. (2018). Efficiency of various sewage sludges and their biochars in improving selected soil properties and growth of wheat (Triticum aestivum). Journal of environmental management, London, 223, 607613. https://doi.org/10.1016/j.jenvman.2018.06.081

Rigby, H. Clarke, B. O. Pritchard, D. L. Meehan, B. Beshah, F. Smith, S. R. \& Porter, N. A. (2016). A critical review of nitrogen mineralization in biosolidsamended soil, the associated fertilizer value for crop production and potential for emissions to the environment. Science of the Total Environment London, 541(541), 1310- 1338. https://doi.org/10.1016/j.scitotenv.2015.08.089

Sampaio, T. F. Guerrini, I. A. Backes, C. Heliodoro, J. C. A. Ronchi, H. S. Tanganelli, K. M. \& Oliveira, F. C. (2012). Lodo de esgoto na recuperação de áreas degradadas: efeito nas características físicas do solo. Revista Brasileira de Ciência Do Solo, 36(5),1637-1645. https://doi.org/10.1590/s010006832012000500028

Santos, H. M. N. Borges, A. A. S. Cândida, A. C. \& Fehr, M. (2010). Educação ambiental e resíduos sólidos em Araguari/MG. Brasil. Revista da Católica, Uberlândia, 2(3), 136-152.

Segura-Muñoz S. I. Takayanagui, A. M. M. Lopes, T. M. Trevilato, T. M. B. \& Hering, S. (2003). Estudo do efeito neurotóxico da exposição ocupacional ao mercúrio, ao chumbo e ao manganês utilizando como ferramenta metodológica a Revisão Sistemática de Literatura. Mundo Saúde 27(4), 589-595.

Souza, M. T. D. Silva, M. D. D., \& Carvalho, R. D. (2010). Revisão integrativa: o que é e como fazer. Einstein (São Paulo), 8(1), 102-106. https://doi.org/10.1590/S1679-45082010RW1134

Maeda, S. Soares, M. T. S. \& Dias, M. V. (2021). Aplicação de resíduos agropecuários, urbanos e industriais em plantios de eucalipto. In: OLIVEIRA, E. B. de PINTO JUNIOR, J. E. (Ed.). O eucalipto e a Embrapa: quatro décadas de pesquisa e desenvolvimento. Brasília, DF: Embrapa, 555-587.

Silva, R.R. Siqueira, E. Q. \& Nogueira, I. S. (2018). Impactos ambientais de efluentes de laticínios em curso d'água na Bacia do Rio Pomba. Revista de Engenharia Sanitária e Ambiental, Rio de Janeiro, 23(2), 217-228. https://doi.org/10.1590/S1413-41522018138062

Silva, M. V. Chaer, G. M. Santos Leles, P. S. dos Resende, A.S. de, Silva, E.V. da, \& Barros, T. D. O. C. (2020). Uso de biossólido em plantios de espécies da Mata Atlântica. Scientia Forestalis, 48(126), 1-14. https://doi.org/10.18671/scifor.v48n126.16

Silva, F. A. de M Nunes, G. M., Zanon, J. A. Guerrini, I. A. \& Silva, R. B. da. (2018). Resíduo agroindustrial e lodo de esgoto como substrato para a produção de mudas de Eucalyptusurograndis. Ciência Florestal, Santa Maria, 28(2), 827-828. https://doi.org/10.5902/1980509832101

Srivastava, V. (2016). Biological response of using municipal solid waste compost in agriculture as fertilizer supplement. Reviews in Environmetal Science and Biotechnology, 15(4), 677-696. https://doi.org/10.1007/s11157-016-9407-9

Straus, E. L. (2013). Normas de utilização de lodos de esgoto na agricultura. In: Bettiol, W. \& Strojaki, T. V Silva, V. R. Somavilla, A. Ros, C. O. Moraes, M. T. Atributos químicos do solo e produtividade de girassol e milho em função da aplicação de composto de lixo urbano. Pesquisa Agropecuária Tropical (Agricultural Research in the Tropics), 43(3), 278-285. https://doi.org/10.1590/S1983-40632013000300002

Strojaki, T. V. Silva, V. R. Somavilla, A. Ros, C. O. \& Moraes, M. T. (2013). Atributos químicos do solo e produtividade de girassol e milho em função da aplicação de composto de lixo urbano. Pesquisa Agropecuária Tropical (Agricultural Research in the Tropics), 43(3), 278-285. https://doi.org/10.1590/S198340632013000300002

Stromberger, M. Shah, Z. \& Westfall, D. G. (2011). High specific activity in low Microbial biomass soils across a not till evapotranspiration gradiente in Colorado. Soil Biology \& Biochemistry. Oxford, 43(1), 97-105. https://doi.org/10.1016/j.soilbio.2010.09.018

Tavares, F. V. \& Monteiro, L. (2014). Indicadores de Eficiência Energética na Indústria de Fertilizantes de Amônia. Sistemas \& Gestão, 9(2), 216-223. https://doi.org/10.7177/sg.2014.v9.n2.a6

Tavella, L. B., Galvão, R. O. Ferreira, R. L. F. Araújo Neto, S. E. \& Negreiros, J. R. S. (2010). Cultivo orgânico de coentro em plantio direto utilizando cobertura viva e morta adubado com composto. Revista Ciência Agronômica, Fortaleza, 41(4), 614-618. https://doi.org/10.1590/S1806-66902010000400014 
Research, Society and Development, v. 11, n. 3, e14711326200, 2022

(CC BY 4.0) | ISSN 2525-3409 | DOI: http://dx.doi.org/10.33448/rsd-v11i3.26200

Tytła, M. Widziewicz, K. \& Zielewicz, E. (2016). Heavy metals and its chemical speciation in sewage sludge at different stages of processing. Environmental Technology, 37(7), 899-908.https://doi.org/10.1080/09593330.2015.1090482

Vaz, L. M. \& Gonçalves, J. L. M. (2002). Uso de biossólidos em povoamento de eucalipto: efeito em atributos químicos do solo, no crescimento e na absorção de nutrientes. Revista Brasileira de Ciência do Solo, Viçosa, 26(3), 747-758. https://doi.org/10.1590/S0100-06832002000300020

Vendrame, P. R.S. Eberhardt, D. N. E. Brito, O. R. Marchão, R. L. Quantin, C. \& Becquer T. (2011). Formas de ferro e alumínio e suas relações com textura, mineralogia e carbono orgânico em Latossolos do Cerrado. Semina: Ciências Agrárias, Londrina, 32(1), 1657-1666. https://doi.org/10.5433/16790359.2011v32Suplp1657

Westphalen, C. Neto J. C. \& Carli Já Zirpoli, M. R. O. Aplicação do lodo de esgoto na agricultura. In: Roméro M. A. Philippi J. R. A. Bruna, G. C. Panorama ambiental da metrópole de São Paulo. São Paulo: Signus 2004. p.124-127.

Yu, H. Zou, W. Chen, J. Chen, H. Yu, Z. Huang, J. Tang, H. Wei, X. \& Gao, B. (2019). Biochar amendment improves crop production in problem soils: A review. Journal of Environmental Management, 232, 8-21. https://doi.org/10.1016/j.jenvman.2018.10.117

Zoghlami, R. I., Hamdi, H., Mokni-Tlili, S., Hechmi, S., Khelil, M. N., Ben Aissa, N., Moussa, M., Bousnina, H., Benzarti, S., \& Jedidi, N. (2020). Monitoring the variation of soil quality with sewage sludge application rates inabsence of rhizosphere effect. International Soil and Water Conservation Research, 8(3), 245-252. https://doi.org/10.1016/j.iswcr.2020.07.007 